\title{
GRUPO OPERATIVO COMO ESTRATÉGIA PEDAGÓGICA EM UM CURSO GRADUAÇÃO EM ENFERMAGEM: UM CONTINENTE PARA AS VIVÊNCIAS DOS ALUNOS QUARTANISTAS*
}

\author{
OPERATIVE GROUP AS A PEDAGOGICAL STRATEGY IN A NURSING \\ GRADUATION COURSE: A CONTINENT FOR THE \\ FOURTH-YEAR STUDENTS' EXPERIENCES
}

\section{GRUPO OPERATIVO COMO ESTRATEGIA PEDAGÓGICA EN UN CURSO DE GRADUACIÓN EN ENFERMERÍA: UN CONTINENTE PARA LAS VIVENCIAS DE LOS ALUMNOS DEL CUARTO ANO}

Roselma Lucchese** Sônia Barros***

\begin{abstract}
Lucchese R, Barros S. Grupo operativo como estratégia pedagógica em um curso de graduação em enfermagem: um continente para as vivências dos alunos quartanistas. Rev Esc Enferm USP 2002; 36(1): 66-74.

\section{RESUMO}

Este estudo teve como objetivo oferecer um espaço para a expressão vivencial do aluno de quarto ano de graduação em enfermagem. Espaço operacionalizado por meio da técnica de grupo operativo, no qual os sujeitos do estudo, centrados na tarefa trocaram experiências e avaliaram sua participação nos grupos. Para compreender o vivencial dos alunos optou-se pela pesquisa qualitativa, utilizando-se como método a pesquisa-ação. A problemática do estudo envolveu o conceito de que a aprendizagem é um processo de socialização que requer mudanças, sendo mobilizadora de sentimentos do aprendiz. O grupo operativo funcionou como espaço continente das vivências dos alunos que explicitaram sentimentos mobilizados em seu processo de formação, impossiveis de serem ignorados pelo educador em enfermagem.
\end{abstract}

PALAVRAS-CHAVE: Aprendizagem. Ensino. Enfermagem. Alunos de enfermagem.

\begin{abstract}
The objetive of this study is to offer a space for the fourth-year students of the nursing school to express their experiences. A space was put in operation by the use of an operative group technique, and the subjects of the study,. centered in the task, exchange experiences and evaluate their participation in the groups. To understand the students' experience, a qualitative study with the research-action method was produced. The problematic of the study involved the concept that learning is a socialization process which demands changes and mobilize the novices' feelings. The operative group worked as a continent for the students' experiences in which they could explain their feelings. Such feelings, mobilized on their graduation process, were impossible to be ignored the nursing teacher.
\end{abstract}

KEYWORDS: Learning. Teaching. Nursing. Students, nursing.

\section{RESUMEN}

Eate estudio tuvo como obetivo ofrecer un espacio para la expresión vivencial del alumno de cuarto año de la graduación en enfermeria. Espacio operacionalizado por medio de la técnica de grupo operativo, en el cual los sujetos el estudio, centrados en la tares, intercambiaron experiencias y evaluaron su participación en los grupos. Para comprender el vivencial de los alumnos fue elegida la pesquisa cualitativa, utilizándose como método la pesquisa-acción. La problemática del estudio implicó el concepto de que el aprendizaje es un proceso de socialización que requiere cambios, siendo capaz de mobilizar los sentimientos del aprendiz. El grupo operativo funcionó como um continente de las vivencias de los alumnos que explicitaron sentimientos estos conocidos por el educador en enfermería.

PALABRAS-CLAVE: Aprendizaje. Ensenanza. Enfermería. Estudiantes de enfermería.

\footnotetext{
* Este artigo é resumo de Dissertação de Mestrado apresentado à Escola de Enfermagem da Universidade de São Paulo,2000.

** Enfermeira, professor auxiliar de ensino I, do curso de Enfermagem da Fundação Educacional de Fernandópolis, Mestre em Enfermagem Psiquiátrica pela EEUSP, Doutoranda do Programa Interunidades da EEUSP; e-mail: roselma@acif.com.br

*** Enfermeira, Professor Doutor do Depto. De Enfermagem Psiquiátrica da Escola de Enfermagem da Universidade de São Paulo.
} 


\section{INTRODUÇÃO}

A vivência profissional no desempenho do papel de educador, interlocutor e iniciador do aluno de graduação na prática da enfermagem, significa-nos mais que dinamismo e dedicação ao saber científico e empírico; abrange compreender o papel do educando, na condição de sujeito que se apropria da realidade da enfermagem. Portanto, preocupa-nos como o aluno vem se apropriando dessa realidade.

O aprender é conduzido pela interação do pensar, sentir e agir, com suas múltiplas relações interpessoais e com o meio, e que segundo Gayotto ${ }^{(1)}$ "depende de processos psicológicos, ou seja, de como educadores e educandos mobilizam suas instâncias psíquicas, no sentido de intermediação enriquecedora entre o mundo interno de cada um e o mundo externo, o que permitirá uma articulação vincular na construção conjunta do conhecimento..."

O convívio com alunos nos proporcionou a escuta de quartanistas de graduação em enfermagem que explicitam a ansiedade nas relações com o trabalho e atividades exigidas pelo curso. Uma dessas, que torna mais conflituoso o ser ou não enfermeiro, é o próprio cotidiano da profissão que, de acordo com Pitta (2) tem como ofício o lidar com a dor, perdas, sofrimento e morte. A autora ainda se refere à execução de tarefas agradáveis ou repulsivas que a profissão impõe ao enfermeiro, sendo necessário um período de ajustes psíquicos internos da pessoa para que possa obter satisfação com as atividades exercidas ou elaborar defesas psicológicas.

Estar preparado para assumir o papel de enfermeiro envolve uma relação social que, para Menzies(3) desencadeia um processo de mudanças sociais significativas. E como toda mudança, mobiliza defesas psíquicas a serem reestruturadas; portanto, motivo gerador e intensificador da ansiedade.

Outro momento também vivido pelo aluno é o interjogo de papéis; para Viorst ${ }^{(4))}$, o abandono de papéis entra nas perdas necessárias que experimentamos nas diversas fases de nossa vida, pelo abandono da auto-imagem antiga e o seguir em frente. O quartanista está prestes a perder o papel de aluno, sente e assusta-se com essa separação, questionando sua própria condição a priori.

Utilizamos a opinião de Ciampone(5) para reforçar a necessidade de voltar o olhar aos aspectos afetivos do educando, com a "criação de espaços para trabalhar sentimentos desde a formação profissional[...] pois, assim, já nos primeiros contatos com a vida profissional na área da saúde, o jovem aprendiz teria a oportunidade de examinar, de ter acesso aos seus sentimentos oriundos desses contatos, discriminando o que é dele e o que é do outro".
Pichon-Rivière(6) afirma, ainda, que cerca de 10\% dos estudantes do nível universitário correm o risco de sofrer sérias dificuldades de aprendizagem, o que acarreta problemas de adaptação social no futuro e que urge o emprego de psicoterapia no meio estudantil e propõe a utilização de técnicas grupais na didática e na aprendizagem dos profissionais de saúde das ciências sociais.

Considerando que o quartanista já tenha vivenciado, nos três anos anteriores, um processo de socialização, o estudo propôs a aplicação do grupo operativo como ajuda ao aluno na expressão e compreensão de sentimentos que emergem das relações do aprendiz com a prática da enfermagem. Para tanto, elegeu os objetivos:

- Oferecer um espaço para a expressão vivencial do aluno de quarto ano de graduação;

- Operacionalizar, por meio de um grupo operativo, trocas relacionais que favorecem o enfrentamento das ansiedades vivenciadas pelos alunos;

- Avaliar a intervenção grupal como estratégia pedagógica a ser articulada no curso de graduação em enfermagem.

\section{REVISÃO TEÓRICA SOBRE GRUPOS OPERATIVOS}

\section{Grupo Operativo: o autor e a obra}

Pichon-Rivière, nascido em Genebra (Suíça) em 25 de junho de 1907 é o psicanalista que introduz a dinâmica de grupos operativos, na década de 40 do século XX. Para Pichon-Rivière( ${ }^{(6)}$ o grupo operativo é constituído de pessoas reunidas com um objetivo comum, chamado de "grupo centrado na tarefa que tem por finalidade aprender a pensar em termos de resolução das dificuldades criadas e manifestadas no campo grupal". O autor desenvolve toda uma teoria em que explicita sua forma de pensar no sujeito, na sua "relação objeto" e no grupo, tendo como base a estrutura vincular modelando a sua intervenção em grupo, atribuindo à técnica um caráter dinâmico e interdisciplinar, empregado na educação (grupos de ensino) e na terapia (grupoterapia).

\section{Alguns principios da Teoria Pichoniana}

A psicologia social de Pichon-Rivière está voltada ao estudo do homem como um ser social, que se relaciona com o outro em grupo. Visualiza o homem com necessidades que são internas que mobilizam ações diante do mundo externo, dando-se um interjogo dialético entre mundo interno/externo.

Para compreensão da técnica elaborada por Pichon-Rivière, denominada grupo operativo, faz-se necessário comentar sobre o ECRO - esquema 
conceitual, referencial e operativo, definido "como um conjunto organizado de conceitos gerais, teóricos, referentes a um setor real, a um determinado universo de discurso, que permite uma aproximação instrumental do objeto particular (conceito)". Por meio do ECRO há a apreensão da realidade que se propõe estudar(7).

Os niveis articulares no grupo relacionados à inserção da pessoa são: verticalidade referente à vida pessoal de cada membro e horizontalidade que é a história grupal, compartilhada entre os integrantes, que surge com base na existência do grupo até o momento presente. Estes niveis representam as histórias do indivíduo e do grupo que se fundem, conjugando o papel a ser desempenhado(8).

Características peculiares da técnica: a) o grupo centrado na tarefa. A mobilização dos elementos do grupo em direção ao' objetivo contratado, mediante a clareza do porque, para que se reúnem e interagem. b) porta-voz, bode expiatório, lider e sabotador: papéis a serem aclarados. $O$ grupo operativo estrutura-se no interjogo de assunção e adjudicação desses papéis que são funcionais e rotativos. c) coordenador e observador: uma visão

pichoniana. Estes papéis têm função assimétrica em relação aos elementos que compõem o grupo, e interliga-se na análise do trabalho grupal. d) os vetores que constituem a escala de avaliação do processo grupal: seus indicadores. Permite analisar a relação entre conteúdos explícitos e implícitos do grupo, no decorrer de seu desenvolvimento, representados neste cone invertido:

\section{Cone Invertido}

$$
\begin{array}{|l}
\text { Afiliação/ } \\
\text { Pertença } \\
\text { Comunicação }
\end{array}
$$

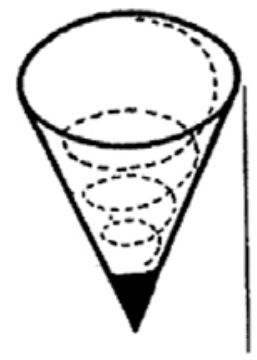

Latente
Pertinência

Aprendizagem

Tele

\section{O uso da dinâmica de grupo na enfermagem: uma profissão voltada para o coletivo}

Trabalhar em grupo torna-se um desafio para a enfermagem, considerando que, para que isso ocorra, é necessária a articulação dás pessoas no desempenho de uma ação em conjunto. Dois fatores são evidentes na prática do enfermeiro, o que nos leva a visualizar dificuldades na ação conjunta; o primeiro, proveniente da observação direta da atividade do enfermeiro, mostra uma desarticulação entre enfermeiro e demais profissionais e destes com o enfermeiro (salvo em algumas instituições) dificultando o trabalho multidisciplinar; o segundo fator está relacionado à formação do profissional que raramente esta preparado para atuar em grupo. Realidade confirmada pela fala de Gayotto; Domingues(9) sobre "um falso pressuposto de que as instituições de ensino e de saúde, entre outras, já trabalhassem ou privilegiassem o grupo como espaço de mudança do seu pequeno universo".

Munari; Rodrigues(10) alertam quanto à necessidade do preparo teórico-vivencial do enfermeiro para desempenhar atividades grupais, no processo de formação profissional, na graduação, uma vez que nem todas as escolas de enfermagem oferecem em seus currículos disciplinas que contemplem especificamente esta modalidade de trabalho. As autoras afirmam que o papel de coordenador de grupo é possível ser desenvolvido pelo enfermeiro, sendo necessário que o profissional faça investimentos na sua formação.

Quanto ao trabalho com grupos no campo da enfermagem, temos observado que muito embora a profissão tenha como característica o relacionar-se com pessoas, outros profissionais, pacientes, familiares, o enfermeiro raras vezes faz uso da intervenção grupal assumindo o papel de coordenador.

\section{METODOLOGIA}

O grupo operativo como intervenção na vivência do aluno quartanista de graduação em enfermagem foi o foco desta pesquisa que tentou vincular uma ação (intervenção da realidade) a um problema percebido durante o contato com estes sujeitos. Segundo Minayo(11) "nada pode ser intelectualmente um problema, se não tiver sido, em primeiro lugar, um problema da vida prática".

Esta foi uma pesquisa qualitativa, que teve como opção utilizar o método pesquisa-ação para alcançar os objetivos almejados, e por permitir, segundo Thiollente(12), a participação ativa do pesquisador na própria realidade dos fatos observados.

\section{Campo de Estudo}

A pesquisa foi realizada na Fundação Educacional de Fernandópolis (FEF). Para tanto houve previamente à coleta de dados, a autorização da instituição, segundo o Termo de Autorização, protocolado em 4 de agosto de 1999, n 1.324/99.

\section{Sujeitos/Atores da Pesquisa}

O grupo social abordado pela pesquisa constituiu-se de alunos que cursavam o quarto ano de graduação em Enfermagem e Obstetrícia na FEF em 1999. Dos 50 alunos matriculados, dez 
participaram voluntariamente da intervenção grupal após convite da pesquisadora, levando-se em consideração as orientações de diversos autores sobre o número ideal de pessoas para a operatividade de um grupo, girando em torno de 8 a 12 pessoas. Um número inferior poderia não oferecer o dinamismo necessário às interações e trocas. Um número superior poderia tornar a comunicação inviável e contribuir para formação de grupos paralelos ou subgrupos.

Esta pesquisa envolveu três momentos de coleta e análise de dados, distintos, porém, interligados por uma seqüência e complementaridade. Um primeiro momento: Correspondeu à fase exploratória, ao serem levantados dados sobre a realidade vivenciada pelos sujeitos, por meio de discussão de grupo, seguindo orientações de Minayo(13) Neste momento, participaram o pesquisador e dez alunos. A discussão foi mobilizada pela questão norteadora - "Conte urna vivência como aluno de quarto ano, que você acha mais importante"; e como questão suporte: - "Essa vivência expressa seus sentimentos como aluno de quarto ano?".

Toda a reunião foi gravada e transcrita, após utilizou-se da análise temática para tratar os dados colhidos, embasadas teoricamente nos trabalhos(14),(13)

Um segundo momento: Esse momento compreendeu a elaboração de um plano de ação para intervenção na realidade. As reuniões grupais contaram com a participação dos sujeitos/alunos, coordenador e observador (um papel fundamental para a técnica pichoniana) que procedeu as anotações do grupo. Os grupos foram analisados sob a forma de crônicas, avaliadas de acordo com os vetores presentes.

Um terceiro momento: constituiu-se de relatos dos alunos que participaram do trabalho, na forma discussão de grupo. Participaram os dez alunos / sujeitos e o pesquisador. A discussão foi norteada pela seguinte questão: "Como foi para o aluno participar das oito reuniões de grupo operativo contractuadas $e$ oferecidas pela pesquisa". Da análise temática surgiram as categorias dispostas de modo que pudessem ser discutidas sob o olhar do pesquisador tendo como suporte trabalhos de outros pesquisadores, em especial, a ótica pichoniana que fundamenta a técnica utilizada.

\section{CONSTRUÇÃO DOS TEMAS}

\section{"O Processo Ensino-Aprendizagem"}

Este tema originou-se de ampla discussão entre os sujeitos da pesquisa, os quais resgataram com freqüência aspectos cognitivos, intelectuais e emocionais que envolvem tal processo. Reforça, assim, a idéia pichoniana de que a aprendizagem é uma apropriação ativa e criativa da realidade, envolve as relações psíquicas, tornando-se algo além do cognitivo, mais complexo e representativo. O tema surgiu do agrupamento de quatro subtemas formulados das falas dos alunos.

"Avaliação do ensino". Ao falarem da vivência de quartanista, os alunos demonstraram sentimentos que refletiram as internalizações ocorridas no processo ensino-aprendizagem. Sentimentos não prazerosos como insegurança, depressão, revolta, angústia, mágoa, decepção, medo: - -... realmente essa questão emocional, as angústias que a gente estava sentindo..."

Os alunos sentiram-se desumanizados neste processo, perceberam que os sentimentos, problemas e conflitos que os atingem não têm espaço para ser discutido: "... esquece que o aluno é humano..."

Jorges; Rodrigues(15) revelaram, em um estudo que identificava os serviços de apoio aos estudantes nas escolas de enfermagem do Brasil, que a maioria delas dispensava apenas orientações pedagógicoadministrativas, formalmente, e uma minoria de escolas voltam a atenção às necessidades dos alunos

"Avaliação do aprendizado: ser avaliado e avaliar ". O processo ensino-aprendizagem envolve a avaliação que se faz necessária diante de um objetivo comum "o promover a aprendizagem", não podendo ser considerada como uma atividade que finda o processo de aprendizagem, tão pouco como algo isolado e estanque. $\mathrm{O}$ avaliar acompanha todo o processo ensino-aprendizagem, deve ser encarado como fonte de mudanças, visando aprimorar e aproximar o aluno do que se pretende ser aprendido.

Para os alunos, a avaliação passou a ser um método de repressão, rotulador, obrigando-os a carregar traços indesejáveis durante toda a vida universitária. Assim, expressaram as seguintes falas: - "... então até hoje traz traços do que você foi no segundo ano de faculdade..."

Conceituaram que este tipo de avaliação não se enquadra em uma avaliação didaticamente adequada. Segundo Lindgren(16)"avaliação consiste na identificação, na mensuração e na interpretação de mudanças no comportamento ou na realização dos alunos, que tenham ocorrido como resultado da aprendizagem".

O correto seria que a avaliação proporcionasse a visualização do que juntos, educando e educador, conseguiram produzir numa parceria. Segundo Luckesi et al.(17), a avaliação deveria ser global e de processo, não somente de momentos, na tentativa de "envolver o aluno no processo do estudo, do fazer, do aprender, do crescer como gente, em perspectiva crítica, humana". 
"Avaliação do docente". Embora alguns estudiosos e a própria vida demonstrem que a aprendizagem ocorre mesmo na ausência do professor, nosso sistema educacional mantém relevante a presença do docente no processo ensino-aprendizagem. Presença estabelecida sob um modelo educacional centrado no professor e não no aluno. Diante do processo ensino-aprendizagem, os alunos adotaram uma postura crítica quanto à figura e conduta do docente, por meio de frases como: - "... parece que eles querem manipular a mente da gente..."

Pelas falas dos alunos, a opinião do professor foi decisiva e marcante para a vida profissional futura. Muitos viram no professor um modelo, identificaramse mais com o professor mais aberto e reflexivo que conseguiu ouvir o educando e ser ouvido, por meio de uma postura acolhedora, estimulando o aluno a assumir seu papel de sujeito da aprendizagem. Segundo Freire ${ }^{(18)}$, este é o educador que assume uma postura política democrática optando por uma ação transformadora. Tal opção não despe o professor de sua responsabilidade diante do ato de conhecer mas, sim, o reafirma ao desafiar "o educando a assumir-se como sujeito do processo de conhecer".

"Relação aluno/professor". O processo ensino-aprendizagem dá-se mediante ações e o envolvimento de pessoas, portanto, é de grande importância compreender melhor as dimensões das relações neste contexto. Para Barreto (19), "o sujeito da educação não é só o aluno, mas é o aluno e o professor em relação, por meio de ou mediados pelo conteúdo". A relação aluno/supervisor docente existe inevitavelmente e os alunos da pesquisa remeteramse a ela dessa forma: _" ... estava com problemas $e$ queria atenção, me dá atenção..."

Os alunos, por meio de suas falas, deixaram claros os conflitos que surgem na relação alunos/ supervisor. Alguns pediram mais atenção e aproximação na relação, julgando ser pouco o valor que o professor atribui ao aluno. Questionaram o pouco envolvimento que o supervisor tem com seu aluno, considerando aquele docente que acompanhou o aluno em campo prático.

Segundo Pichon-Rivière(20), o "processo de aprendizagem deve ser compreendido como um sistema de fechamento e abertura que funciona dialeticamente. Fecha-se em um determinado momento, abrindo-se em seguida, para voltar a se fechar posteriormente".

\section{"A Assistência de Enfermagem: aprendendo a fazer"}

No decorrer do processo ensino-aprendizagem o aluno vai internalizando aspectos da profissão e elaborando conceitos próprios que o auxiliarão ou não a assumir o papel de profissional. Para Gonzales(21), "trabalhar com pessoas, dentro de uma concepção bio- psico-sócio-espiritual, como tem sido a pretensão da enfermagem, requer do enfermeiro o desenvolvimento de sua autopercepção que lhe possibilitará uma melhor compreensão de si mesmo, conseqüentemente, contribuirá para o estabelecimento de um relacionamento mais solidário com a clientela e a própria equipe de enfermagem."

"Ser enfermeiro". Ao atuar no campo prático o aluno planeja e executa assistência e desta atividade tira impressões e ocorrem internalizações, das quais formulam ou reformulam matrizes de aprendizagem. Neste processo é a história vertical: individual do aluno; e a história horizontal: o aluno no contexto enfermagem. Para Gayotto(1), "essa aproximação entre conhecimentos antigos e atuais, proporcionará consciência inédita da informação e, a partir disso, a possibilidade de novos recursos com os quais o educando irá inovar sua maneira de ser e de estar no mundo."

Os sujeitos da pesquisa falaram de trabalho árduo e de dedicação: - "... eu dei o sangue naquela unidade, fiz tudo o que podia..."

Foi significativamente expressivo o senso de responsabilidade dirigido ao enfermeiro pelos alunos. São várias as falas que atribuíram esta característica ao profissional, sendo gratificante ouvir do aluno sua percepção de fatores positivos e negativos do ser enfermeiro por reafirmar o processo dialético do aprender, além do fato de estimular o senso crítico. Estabelece-se o desenvolver qualitativo de seu conhecimento.

"Trabalho em grupo". Na opinião dos alunos o enfermeiro não atua só mas depende diretamente de outros profissionais. Vale a pena citar a consideração de Shimizu; ciampone (22), de "que o trabalho é uma prática de caráter social; assim sendo, gera fenômenos coletivos no espaço microssocial, aqui entendidos como o espaço do grupo no trabalho". E os alunos identificaram a necessidade do enfermeiro integrar-se mais na equipe, justamente para melhorar a assistência: "... é por que a tendência é trabalhar em grupo não ser individualista, não ter individualismo..."

A visão dos alunos sobre o trabalho em grupo foi a integração de ações entre uma equipe multidisciplinar. No campo grupal, existem inesgotáveis possibilidades de aprendizagem e de crescimento profissional. Eles também deixaram claro a idéia de melhoria de qualidade do trabalho quando a interdisciplinaridade ocorre.

"O sistema de saúde". Para iniciar a discussão da elaboração deste subtema fizemos uso de um trecho do livro de Germano(23): "em decorrência da monopolização da economia, as práticas de saúde e o exercício da medicina e da enfermagem, em particular, sofreram um processo acentuado de privatização e de 
especialização excessivas. Esta privatização diz respeito à crescente organização empresarial de que se reveste a prestação da assistência médica, na atualidade. Em tal contexto os' serviços de saúde são transformados em mercadorias que, pelo alto preço, só podem ser consumidos pelas classes dominantes".

Esta é a realidade da saúde no país, com todo seu comprometimento socioeconômico-cultural. Não se pode fugir a essa realidade, portanto, é nela que se insere a atividade de nosso aluno tendo como impressão: - "... o preconceito do hospital, mesmo, do setor administrativo do hospital, que dá prioridade às áreas particulares, e chega o SUS... eu acho que não deveria ter essa discriminação..."

Os alunos identificaram a baixa qualidade da assistência prestada pelo sistema de saúde. Por um lado uma assistência desqualificada justificada pelo insuficiente repasse de verba pelo SUS e, de outro lado, uma pessoa necessitando ser cuidada.

Naturalmente, eles elegeram o paciente de SUS o melhor para ser cuidado. A naturalidade da escolha deu-se pela segurança pois este foi um campo conhecido, e de certa forma não ameaçou tanto o aluno com um paciente mais exigente.

\section{"O Futuro"}

Este tema representou uma constante no pensamento dos alunos que findaram um curso de $\bullet$ formação profissional. Uma etapa na vida que exigiu tomada de decisões mais amadurecidas em relação à profissão, deixando o aluno em uma situação aparentemente conflituosa: - "... no fundo se tá morrendo de medo de acabar, mas também não se vê a hora que acaba..."

Assumir o novo papel profissional representou mudança e, segundo Pichon-Rivière( ${ }^{(6)}$. Nesta situação, a pessoa tem mobilizado os dois medos básicos geradores de ansiedade. $\mathrm{O}$ primeiro medo diz respeito ao medo da perda, relativo à fantasia de perder o conhecimento e o papel já adquirido pelo aluno; o segundo medo é de ataque ao desconhecido, paranoicamente tem- se medo do que não se conhece, podendo resultar num efeito negativo em se adaptar à nova realidade.

Mas a necessidade de buscarem um futuro é a mola propulsora dos que assim se expressaram: - "... ir embora, de, sabe assim, trabalhar mesmo..."

O futuro pode ser ameaçador aos alunos que se sentiram inseguros, ansiosos, até resistentes às mudanças mas, por outro lado, eles tiveram motivação para assumir o papel de enfermeiro. Esta situação, segundo Quiroga(24), representa o interjogo subjetivo entre pares contraditórios: necessidade e satisfação. A necessidade mobiliza o sujeito a buscar o objeto de satisfação e mediante esta experiência a necessidade transforma-se, ocorre internalização do objeto e o sujeito também se modifica.

\section{O GRUPO OPERATIVO: CRÔNICAS}

Apresentamos uma sintese dos vetores analisados pelas crônicas das oito reuniões, seguidas de seus pares contraditórios:

Pertença: em todas as reuniões direcionaram-se reafirmando a pertença com o comparecimento e pela explicitação das dificuldades, sugerindo mudanças, atualização. Mobilizaram as representações internas no sentido de aceitação do outro e a expressão do sentimento surgido no campo grupal, para aclaramento das dúvidas.

Cooperação: articularam-se, complementando as colocações uns dos outros, compartilharam vivências, num movimento crescente de se dispor a ouvir o outro, buscando espaço para também expor convergências e divergências. Impediram por algumas vezes o sabotamento do grupo.

Pertinência: permaneceram de início na condição de pré-tarefa, marcada por momentos de tensão, remetendo o grupo à condição de defesa, depositando no outro as culpas ou tentando encontrar um culpado (lidando com os medos básicos). No decorrer das reuniões mobilizaram as resistências, iniciando um posicionamento em que se direcionaram para execução da tarefa.

Comunicação: detectou-se ruídos na comunicação em alguns momentos grupais, por meio de conversas paralelas, momentos de exaltação e desvio da tarefa; em outros, fluiu dinamicamente entre os sujeitos da pesquisa, tornando possivel a compreensão do outro e a identificação de momentos tensos de conflito da relação abordada pelo grupo.

Aprendizagem: apropriaram-se dos discursos; visualizaram seu próprio crescimento no processo ensino-aprendizagem, resgatando sentimentos emergentes destes como alunos, por meio de vivências negativas e positivas na relação com o professor, colegas e pacientes, identificando os aspectos pessoais e do outro que interferiram, favorecendo ou dificultando essa relação; reelaboraram maneiras criativas de apropriação da realidade futura, explorando o aqui e agora com base nas trocas que fizeram dos medos (perda/ataque) que trouxeram nas matrizes construídas nas diferentes experiências vivenciadas, diminuíram as ansiedades básicas e, assim, prepararam-se para enfrentar os obstáculos imaginários que permearão o futuro.

Tele - inicialmente mobilizaram sentimentos e clima de aceitação pela otimização dos discursos. Estabeleceu-se gradativamente clima favorável para a expressão de opiniões e sentimentos convergentes e divergentes e afetivamente houve uma estabilidade com tele positiva. 
Crônica I - Pares contraditórios - vítima $\mathbf{x}$ culpado; teoria $\mathrm{x}$ prática

Crônica II - Pares contraditórios - ser avaliado x auto-avaliar

Crônica III - Pares contraditórios - amor $\mathbf{x}$ ódio

Crônica IV - Pares contraditórios - ser desejado $\mathbf{x}$ ser rejeitado; distância $\mathbf{x}$ aproximação

Crônica V - Pares contraditórios - enfermeiro ideal $\mathbf{x}$ enfermeiro real

Crônica VI - Pares contraditórios - papel aluno no grupo x profissional no grupo; eu $\mathbf{x}$ outro; confiar $\mathbf{x}$ desconfiar

Crônica VII - Pares contraditórios - assistir com qualidade $\mathbf{x}$ assistir desqualificado; pobre $\mathbf{x}$ rico; SUS $\mathbf{x}$ Particular; impostos $\mathbf{x}$ gratuidade

Crônica VIII - Pares contraditórios - aluno x profissional; dependência $\mathbf{x}$ independência; comodidade $\mathbf{x}$ busca; ideal $\mathbf{x}$ realidade

\section{A AVALIAÇÃo}

\section{Avaliando o grupo operativo}

Os discursos dos alunos explicitaram a experiência grupal de forma dialética, tratando o grupo como um espaço continente da expressão de si e conhecimento do outro, de aprendizagem para lidar com sentimentos originários das relações inclusas no processo ensino-aprendizagem e de autoconhecimento na reelaboração de vínculos.

Expressão de si e reconhecimento do outro. Expressarem-se no espaço grupal tem suas peculiaridades: -- "... quando está em grupo, você falando é diferente..."

$\mathrm{O}$ aprender na relação com o outro no grupo também foi abordado pelos alunos da pesquisa, que ampliaram conhecimentos intercambiando vivências, críticas e sentimentos (mútua representação interna).

Lidando com sentimentos no espaço grupal. Esta característica do grupo operativo identificada pelos alunos convergiu com uma afirmação de Pichon-Rivière(6), que os grupos operativos têm sua "atividade centrada na mobilização de estruturas estereotipadas, dificuldades da aprendizagem e comunicação provocadas pelo montante de ansiedade despertada por toda mudança".

No grupo operativo houve uma grande vantagem: "o proporcionar, a seus integrantes, uma ação corretora desses vínculos". Os alunos identificaram este espaço para explicitar sentimentos diversos. Iniciando, falaram da satisfação de participar das reuniões de grupo operativo: -- "Pra mim foi bom em todos os sentidos..."
Conforme os alunos no grupo operativo foram ratificando e reelaborando estruturas vinculares, a ansiedade fragmentou-se, tornando-se desvendada, levando a um melhor conhecimento de si e do outro. Como conseqüência, temos sujeitos mais críticos, mais plásticos e adaptáveis à realidade, capazes de se apropriarem ativamente da mesma.

Reelaboração de estruturas vinculares. Pelos discursos dos alunos, foi possivel detectar a construção do ECRO grupal que se efetivou durante as reuniões de grupo operativo. Isto é, cada integrante levou para o grupo seu esquema de referência, interagindo uns com os outros, utilizando como instrumento a comunicação, foram juntos elaborando um esquema referencial comum. Este processo configurou as voltas em espiral, propícias à aprendizagem.

Os alunos mantiveram a dialética do mundo interno e do mundo externo ao falarem de seu crescimento e amadurecimento, justamente por reconhecerem que nem tudo foi gratificante. O grupo foi abordado como objeto bom (aquele que se deseja, quer proximidade), continente de sua vivência, sem desmerecer as dificuldades encontradas ao explicitarem dificuldade e dor na relação com o outro: - "... ajudou muito no nivel de crescimento..."

Para Pichon-Rivière(6) , um grupo operativo que se propõe a romper com estereótipos, centrando-se na tarefa, torna o latente explícito na dinâmica grupal. Para tanto, instrumentaliza o campo grupal com a comunicação e mecanismos de assunção e adjudicação de papéis. Segundo o autor, estas são condições para que os integrantes modifiquem seus vínculos externos e internos.

\section{Apreensão da Dinâmica Grupal}

O termo utilizado nesta categoria foi estrategicamente identificado pelos sujeitos da pesquisa. Por entenderem que apreender é algo que vai além do tomar conhecimento, inclui o tomar para si, entender, compreender, acredito que só se possa apreender realmente algo que se vivencia prática e teoricamente. Foi o que se apresentou na análise desta categoria, isto é, os alunos ao vivenciarem a discussão sobre os temas disparadores nas reuniões de grupo operativo mobilizaram estruturas vinculares, no interjogo de assunção e adjudicação de papéis, na dialética mundo interno/mundo externo e apreenderam a dinâmica da técnica pichoniana.

Segundo Abrahão(25), a apreensão "trará um significado ao aprendido, permitindo uma transformação de seu conteúdo e uma modificação do meio através da devolução crítica desse objeto do conhecimento transformado".

Denominando a técnica aplicada na pesquisa. Nos discursos dos alunos, houve uma 
constante denominação da técnica aplicada na pesquisa: - "... eu nunca tinha participado de um grupo operativo..."

A participação em um grupo operativo foi identificada pelos alunos como uma técnica nova, participativa, enriquecedora do conhecimento sobre grupo e houve destaque nos momentos em que o grupo foi terapêutico.

Vivenciando o grupo operativo como um compromisso e uma experiência de vida. $O$ grupo operativo era desconhecido e foi explorado pelos alunos. Novas experiências conferem às pessoas maior plasticidade e capacidade de problematizar o cotidiano, estabelecendo diferentes relações nos distintos grupos que participam: no trabalho, na escola, na familia. O grau de compromisso que os sujeitos da pesquisa mantiveram foi significativo. Esteve visivel no vetor pertença, permanentemente positivo em todas as reuniões grupais.

Compartilhando sentimentos e experiências. Relatando a história horizontal deste grupo, os alunos falaram de um espaço que fora continente de sua história vertical. Espaço onde puderam expor sentimentos próprios e aprenderam com os sentimentos dos outros: _"... é, pude compartilhar... a mesma coisa em relação a sair do quarto ano..."

Foi neste compartilhar que o grupo operativo propiciou o enriquecimento das experiências uns dos outros, elaborando um marco referencial comum, isto é, o ECRO grupal.

Reestruturando as representações internas. Os alunos acabaram por identificar o processo de reestruturação interna dos vínculos ocorrido nos grupos como se pode perceber nesta fala: — "... só eu, buscando dentro de mim mesmo..."

A condição acima relatada foi essencial para tornar o "centramento" na tarefa (pertinência) coerente com o objetivo contrato, levando a esta reestruturação das representações internas, às quais o aluno se referiu.

Mobilizando ressonâncias internas para busca de soluções. Fazendo uso da dialética grupal, eles falaram de que forma o grupo contribuiu na busca de soluções para problemas na vida real. Expressaram uma vivência na qual não conseguiram respostas prontas e acabadas, mas no momento viram a realidade sob outra ótica. No campo grupal, trocaram experiências e conseguiram reelaborar vínculos, tornando-se seres ativos e críticos a ponto de perceberem que os atores da vida real foram eles próprios, que intervieram na realidade: — "... percebi que não tenho que dar importância pra certas coisas..."

\section{Indicando a aplicação do grupo operativo no processo ensino-aprendizagem}

Após identificarem e apropriarem-se da técnica pichoniana, os alunos indicaram os momentos de que mais necessitam de um grupo operativo no processo ensino-aprendizagem. Esses momentos foram relacionados tendo como base a experiência de aprendiz.

Aplicar o grupo operativo em todo o processo ensino-aprendizagem. Assim indicaram a técnica: - "... o grupo operativo na questão do ensino-aprendizagem..."

Complementaram que esta pode ser aplicada com caráter mais abrangente e incluso na grade curricular. Nas opiniões expressas, os alunos identificaram o estágio como o momento mais necessário para uma intervenção grupal. Sem dúvida, foi no cotidiano da prática de enfermagem que eles se encontraram mais expostos às relações com o objeto do conhecimento da profissão e em relação com o outro (paciente, docente/ supervisor).

Fazer uso do grupo operativo em seu cotidiano. Esta pesquisa não só proporcionou uma intervenção na realidade do sujeito como aluno, mas foi por eles identificada como um modelo para trabalhar com grupos, revelando intenções de utilização da técnica, aqui apreendida, em seus cotidianos, como pode ser percebido: - "... (usar do grupo ) em você, na sua pessoa e na sua vida profissional..."

Trabalhar com grupos de uma forma produtiva requer conhecimento e preparo. Existe um contexto teórico-prático sobre grupos, resultando em diversas técnicas e abordagens grupais. Portanto, o profissional que se dispõe a trilhar nesta direção tem de estar ciente desta diversidade, apropriar-se do conteúdo técnicoprático que mais se adequar e atuar efetivamente.

\section{CONSIDERAÇÕES FINAIS}

Este trabalho desvendou sentimentos e situações ocorridas durante a formação dos alunos \sujeito, que foram facilitadores ou dificultadores do ensinar e aprender. Aqui, o grupo operativo revelou uma excelente estratégia didática, continente para a expressão dos alunos que, segundo suas opiniões, deveria ser empregada durante todo o processo ensinoaprendizagem para acompanhar a formação profissional e, em especial, durante sua aprendizagem prática.

Aspecto relevante e freqüente nas falas dos alunos durante as reuniões grupais foi a mobilização dos medos básicos (perda e ataque) que a aprendizagem e o próprio amadurecimento os expôs diante do novo, do desconhecido, do abdicar-se de papéis conhecidos e 
assumir papéis novos. Estas situações vividas no processo exigiram dos alunos um enfrentamento da realidade e cada um se instrumentalizou como pôde, com recursos próprios.

Concluindo as considerações sobre a operatividade do grupo, faz-se necessário destacar a síntese dos vetores pertença, cooperação, comunicação, pertinência, aprendizagem e tele, analisados anteriormente, por meio dos quais ficou evidente a produtividade grupal.

É com a sensação de muito ter aprendido com os sujeitos alunos deste estudo que realizo esses comentários finais. Alunos que operativamente expressaram sentimentos emergentes de seus contatos com o ser enfermeiro, reelaborando conceitos e matrizes de aprendizagem, resultando na elaboração de projetos. Projetos para enfrentamento do futuro, ao utilizarem o campo grupal para expor e discutir as dificuldades da própria aprendizagem e de expectativas frente à profissão, num movimento de resolução dos problemas. Concluímos com uma afirmativa de Bleger (26)"-... toda aprendizagem bem realizada e toda educação é sempre, implicitamente, terapêutica."

\section{REFERÊNCIAS BIBLIOGRÁFICAS}

(1) Gayotto MLC. O ato de aprender. São Paulo; 1999. [Apostila do Curso de Formação de Coordenador de Grupo Operativo Instituto Pichon-Rivière/ Centro de estudos dos fenômenos grupais

(2) Pitta A. Hospital dor e morte como oficio. $3^{4}$ ed. São Paulo: Afiliada; 1994

(3) Menzies I. O funcionamento das organizações como sistemas sociais de defesa contra a ansiedade. Trad. de Arackcy Martins Rodrigues. São Paulo: Fundação Getúlio Vargas; 1970.

(4) Viorst J. Perdas necessárias. Trad de Aulyde Soares Rodrigues. $18^{\mathrm{a}}$ ed. São Paulo: Melhoramentos; 1999.

(5) Ciampone MHT. Grupo operativo: construindo as bases para o ensino e a prática na enfermagem. [tese] São Paulo (SP): Escola de Enfermagem das USP; 1998.

(6) Pichon-Rivière H. O processo grupal. Trad. de Marco Aurélio Fernandes Velosso. 2a ed. São Paulo: Martins Fontes; 1986.

(7) Lema VZ. Conversaciones com Enrique Pichon-Rivière: sobre el arte y la locura. Buenos Aires: Ediciones Cinco; 1997.

(8) Bernstein M. Contribuição de Pichon-Rivière à psicoterapia de grupo. In: Osório LC, organizador. Grupoterapia hoje. Porto Alegre: Artes Médicas; 1989. p.108-32.

(9) Gayotto MLC, Domingues I. Liderança: aprenda a mudar em grupo. $3^{4}$ ed. Petrópolis: Vozes; 1998.

(10) Munari DB, Rodrigues ARE Enfermagem e grupos. Goiânia: $\mathrm{AB} ; 1997$.

(11) Minayo MCS, organizador. Pesquisa social: teoria, método e criatividade. $9^{\mathrm{a}}$ ed. Petrópolis: Vozes; 1998.
(12) Thiollente M. Metodologia da pesquisa-ação. São Paulo: Cortez; 1985.

(13) Minayo MCS. O desafio do conhecimento: pesquisa qualitativa em saúde. São Paulo: Hucitec/Abrasco; 1992.

(14) Bardin L. Análise de conteúdo. Lisboa: Edições 70; 1977.

(15) Jorge MSB, Rodrigues ARE Serviço de apoio ao estudante oferecidos pelas escolas de enfermagem no Brasil. Rev Lat Am Enf 1995; 3(2): 59-68.

(16) Lindgren HC. Psicologia na sala de aula: o professor e o processo ensino-aprendizagem. Rio de Janeiro: Livros Científicos; 1977.

(17) Luckesi C, organizador. Fazer universidade: uma proposta metodológica. 9ª ed. São Paulo: Cortez; 1997.

(18) Freire P. Estrutura do ensino atual. In: Freire P, PichonRivière E. O processo educativo segundo Paulo Freire e Pichon-Rivière. $3^{4}$ ed. Petrópolis: Vozes; 1991. p. 41-3.

(19) Barreto JC. O agente social nos grupos operativos e nos círculos de cultura. In: Freire P, Pichon-Rivière E. O processo educativo segundo Paulo Freire e Pichon-Rivière. $3^{4}$ ed- Petrópolis: Vozes; 1991. p. 59-61.

(20) Pichon-Rivière E. Teoria do vínculo. $5^{4}$ ed. São Paulo: Martins Fontes; 1995

(21) Gonzales RMB. Autopercepção - um trajeto vivenciado por enfermeiras. In: Gonzales RMB, Beck CLC, Denardin MdeL. Cenário de cuidado: aplicações de teorias de enfermagem. Santa Maria: Pollotti; 1999. p. 15-60.

(22) Shumizu HE, Ciampone MHT. Sofrimento e prazer no trabalho vivenciado pelas enfermeiras que trabalham em unidade de terapia intensiva em um hospital escola. Rev Esc Enferm USP 1999; 33(1):35-106.

(23) Germano RM. Educação e ideologia da enfermagem no Brasil. 2a ed. São Paulo: Cortez; 1985.

(24) Quiroga AP. Enfoques y perspectivas en psicologia social: desarrollos a partir del pensamiento de Enrique PichonRivière. Buenos Aires: Ediciones Cinco; 1988.

(25) Abrahão S. Prefácio. In: Freire P, Pichon-Rivière E .0 processo educativo segundo Paulo Freire e Pichon-Rivière. $3^{4}$ ed. Petrópolis: Vozes; 1991. p. 7-9.

(26) Bleger J. Temas de psicologia: entrevista e grupos. São Paulo: Martins Fontes; 1980.

\section{Artigo recebido em 13/08/01}

\section{Artigo aprovado em 19/07/02}

